\title{
GMR
}

\section{Effect of GSTM1, GSTT1, and GSTP1 IIe105Val polymorphisms on susceptiblity to gestational diabetes mellitus}

\author{
Y.H. Qiu', Y.L. Xu' ${ }^{3}$ and W.H. Zhang ${ }^{2}$ \\ ${ }^{1}$ Obstetrics and Gynecology Department, \\ The Second Affiliated Hospital of Shaanxi University of Chinese Medicine, \\ Xianyang, China \\ ${ }^{2}$ Surgery Department, \\ The Second Affiliated Hospital of Shaanxi University of Chinese Medicine, \\ Xianyang, China \\ ${ }^{3}$ Oncology Department, \\ The Second Affiliated Hospital of Shaanxi University of Chinese Medicine, \\ Xianyang, China \\ Corresponding author: W.H. Zhang \\ E-mail: zhangweihongo@163.com \\ Genet. Mol. Res. 15 (2): gmr.15027711 \\ Received September 23, 2015 \\ Accepted December 22, 2015 \\ Published June 3, 2016 \\ DOI http://dx.doi.org/10.4238/gmr.15027711
}

\begin{abstract}
We investigate the role of the GSTM1, GSTT1, and GSTP1 IIe105Val genetic polymorphisms in the susceptibility to gestational diabetes mellitus. A total of 223 pregnant women with gestational diabetes mellitus and 265 healthy pregnant women were examined at The Second Affiliated Hospital of Shaanxi University of Chinese Medicine from May 2013 to November 2013. Genotyping for detection of GSTM1, GSTT1, and GSTP1 IIe105Val polymorphisms was conducted using the restriction fragment length polymorphismpolymerase chain reaction. There were statistically significant differences between patients with gestational diabetes mellitus and control subjects in terms of age $\left(\chi^{2}=6.68, \mathrm{P}=0.01\right)$ and $\mathrm{BMI}(t=7.56$,
\end{abstract}


$\mathrm{P}<0.001)$ levels of HDL-C $(t=2.62, \mathrm{P}=0.005)$ and LDL-C $(t=3.98$, $\mathrm{P}<0.001)$. By the chi-square test, we found significant differences between the present and null genotype distributions of GSTM1 $\left(\chi^{2}\right.$ $=10.95, \mathrm{P}=0.0009)$. Null genotype of GSTM1 could influence the susceptibility to gestational diabetes mellitus compared to the present genotype [adjusted OR $(95 \% \mathrm{CI})=1.85(1.26-2.72)]$. However, the unconditional logistic analysis revealed that GSTT1 and GSTP1 IIe105Val polymorphisms could not influence the risk of gestational diabetes mellitus in a Chinese population. In summary, we suggest that the GSTM1 gene polymorphism could influence the susceptibility to gestational diabetes mellitus in a Chinese population.

Key words: GSTM1; GSTT1; GSTP1 IIe105Val; Polymorphism; Gestational diabetes mellitus

\section{INTRODUCTION}

Gestational diabetes mellitus is defined as carbohydrate intolerance during pregnancy (Metzger et al., 2007). The etiology of gestational diabetes mellitus is not well-understood. The pathogenesis of gestational diabetes mellitus involves many complex environmental and lifestyle factors, such as pregnancies at an older age, high pre-pregnancy weight and BMI, hydramnios, a history of gestational diabetes mellitus, a history of type 2 diabetes, vaginal candida infection, and a history of gestational diabetes (Kühl, 1991; Damm, 1998; Kopp, 2005; Anna et al., 2008; Savitz et al., 2008; Sella et al., 2013; Moon et al., 2015). However, not all pregnant women exposed to certain risk factors go on to develop gestational diabetes mellitus, suggesting that hereditary factors may contribute to the occurrence of this disease. Currently, many epidemiologic studies have shown that certain genes, such as melatonin receptor type 1B (MTNR1B), lipoprotein lipase gene, potassium channel voltage gated KQT-like subfamily Q, member 1 (KCNQ1), methylenetetrahydrofolate reductase (MTHFR), factor V Leiden (FVL), and adiponectin gene and adenosine deaminase, contribute to the susceptibility to gestational diabetes mellitus (Khan et al., 2014; Ao et al., 2015; Li et al., 2015a; Takhshid et al., 2015a,b).

Glutathione-S-transferase (GST) is a family of cytosolic enzymes that have a critical role in catalyzing the conjugation of glutathione with a broad spectrum of endogenous and exogenous compounds, detoxifying environmental toxins and preventing reactive oxygen species-mediated cell injury in the body (Strange et al., 1998; Hayes et al., 2005). Three functional genes have been found in the GST family: GST Mu 1 (GSTM1), GST Theta 1 (GSTT1), and GST Pi 1 (GSTP1). The gene variations of GSTs can alter the expression of enzyme and affect their detoxification ability. In the present study, we investigate the role of the GSTM1, GSTT1, and GSTP1 IIe105Val genetic polymorphisms in the susceptibility to gestational diabetes mellitus.

\section{MATERIAL AND METHODS}

\section{Patients}

A total of 223 pregnant women with gestational diabetes mellitus were examined at The Second Affiliated Hospital of Shaanxi University of Chinese Medicine from May 2013 
to November 2013. The pregnant women with gestational diabetes mellitus aged 20-40 years old. The gestational diabetes mellitus was diagnosed according to the criteria established by the American Diabetes Association (2008), with gestational age being between 24 and 28 weeks and the overnight glucose tolerance test being $75 \mathrm{~g}$ at $2 \mathrm{~h}$ after an overnight fast. The exclusion criteria for patients were pre-existing diabetes, abnormal result in a glucose screening test prior to gestational age being 24th week, multiple gestations, liver or kidney disease, or endocrine disorders.

A total of 265 pregnant women without gestational diabetes mellitus were randomly recruited from pregnant women who received regular prenatal care in The Second Affiliated Hospital of Shaanxi University of Chinese Medicine from May 2013 to November 2013. The exclusion criteria were control subjects who had a history of hypertension, diabetes, multiple gestations, liver or kidney disease, or endocrine disorders.

The biochemical data were collected by face-to-face interview from a self-designed questionnaire. The clinical data were collected from medical records. The demographic information included gender, age, body mass index (BMI), tobacco use (smoking), alcohol consumption, and history of gestational diabetes mellitus. The clinical information included total cholesterol (TC), triglycerides (TG), low-density lipoprotein cholesterol (LDL-C), and high-density lipoprotein cholesterol (HDL-C). All patients and subjects provided written informed consent. the Second Affiliated Hospital of Shaanxi University of Chinese Medicine approved the performance of this study.

\section{DNA extraction and genotyping}

Peripheral venous blood was drawn from patients and control subjects in this study. DNA was extracted from the blood samples using the Qiagen blood mini kit (Qiagen, Hilden, Germany) following the manufacturer's recommendation. Genotyping for detection of GSTM1, GSTT1, and GSTP1 IIe105Val polymorphisms was conducted using the restriction fragment length polymorphism-polymerase chain reaction (RFLP-PCR) method. The forward and reverse primers for GSTM1, GSTT1, and GSTP1 IIe105Val polymorphisms were designed using the Sequenom Assay Design 3.1 software (San Diego, CA, USA). The PCR conditions were as follows: started at $95^{\circ} \mathrm{C}$ for 5 min for initial denaturation; followed by 35 cycles of amplification with denaturation at $95^{\circ} \mathrm{C}$ for $30 \mathrm{~s}$, annealing at $56^{\circ} \mathrm{C}$ for $30 \mathrm{~s}$, and extension at $72^{\circ} \mathrm{C}$ for $30 \mathrm{~s}$; and a final extension step of $72^{\circ} \mathrm{C}$ for $5 \mathrm{~min}$ for all the polymorphic sites. The resulted fragments were electrophoresized on $2 \%$ agarose gel stained with ethidium bromide to determine the genotypes of the subjects for all the polymorphic sites. To confirm the genotyping results, $10 \%$ PCR-amplified DNA samples were examined by DNA sequence, and the results were $100 \%$ concordant.

\section{Statistical methods}

The statistical variation within the demographic variables of the two study groups was done using the chi-square test for the categorical data and the Student $t$-test for continuous variables. Conformation to Hardy-Weinberg equilibrium was tested using the chi-square test or the Fisher exact test. To evaluate the association between GSTM1, GSTT1, and GSTP1 IIe105Val polymorphisms and gestational diabetes mellitus risk, the unconditional logistic regression analysis was used to calculate adjusted odds ratio (OR) along with their $95 \%$ 
confidence intervals (CIs). The ORs and $95 \% \mathrm{CI}$ were adjusted for potential confounding factors. Statistical analysis was conducted using the SPSS 17.0 package (SPSS Inc., Chicago, IL, USA). $\mathrm{P}<0.05$ indicated statistical significance.

\section{RESULTS}

The mean ages of patients were $31.52 \pm 9.25$ years, and were $28.21 \pm 9.83$ years for controls (Table 1). There were statistically significant differences between patients with gestational diabetes mellitus and control subjects in terms of age $\left(\chi^{2}=6.68, \mathrm{P}=0.01\right)$ and BMI $(t=7.56, \mathrm{P}<0.001)$ levels of HDL-C $(t=2.62, \mathrm{P}=0.005)$ and LDL-C $(t=3.98, \mathrm{P}<0.001)$. However, no significant differences were found in gestational age $(t=0.39, \mathrm{P}=0.35)$, smoking $\left(\chi^{2}=2.18, \mathrm{P}=0.14\right)$, alcohol consumption $\left(\chi^{2}=0.06, \mathrm{P}=0.81\right)$, or levels of TC $(t=1.42, \mathrm{P}=$ $0.08)$ or TG $(t=1.57, \mathrm{P}=0.06)$.

The chi-square test revealed that the genotype frequencies of GSTP1 IIe105Val did not deviate from the Hardy-Weinberg equilibrium in the control group, and the $\mathrm{P}$ value for Hardy-Weinberg equilibrium was 0.51 (Table 2). There was significant difference in genotype distributions in terms of GSTM1 $\left(\chi^{2}=10.95, \mathrm{P}=0.0009\right)$. However, No significant differences were observed in the genotype distributions with respect to GSTT1 $\left(\chi^{2}=0.99, \mathrm{P}=0.32\right)$ and GSTP1 IIe105Val $\left(\chi^{2}=1.78, \mathrm{P}=0.41\right)$. Null genotype of GSTM1 could influence the susceptibility to gestational diabetes mellitus compared to the present genotype, and the adjusted OR $(95 \% \mathrm{CI})$ was 1.85 (1.26-2.72). However, the unconditional logistic analysis revealed that GSTT1 and GSTP1 IIe105Val polymorphisms could not influence the risk of gestational diabetes mellitus in a Chinese population.

Table 1. Characteristics of patients with gestational diabetes mellitus and control subjects.

\begin{tabular}{|c|c|c|c|c|c|c|}
\hline Variables & Patients $(\mathrm{N}=223)$ & $\%$ & Controls $(\mathrm{N}=265)$ & $\%$ & Chi-square test or Student $t$-test & $P$ value \\
\hline Age (years) & \multicolumn{2}{|c|}{$31.52 \pm 9.25$} & \multicolumn{2}{|l|}{$28.21 \pm 9.83$} & 3.81 & $<0.001$ \\
\hline$<30$ & 106 & 47.53 & 157 & 59.25 & & \\
\hline$\geq 30$ & 117 & 52.47 & 108 & 40.75 & 6.68 & 0.01 \\
\hline Gestational age & \multicolumn{2}{|c|}{$27.71 \pm 4.87$} & \multicolumn{2}{|c|}{$27.53 \pm 5.12$} & 0.39 & 0.35 \\
\hline BMI $\left(\mathrm{kg} / \mathrm{m}^{2}\right)$ & \multicolumn{2}{|c|}{$30.72 \pm 5.64$} & \multicolumn{2}{|c|}{$27.15 \pm 4.80$} & 7.56 & $<0.001$ \\
\hline$<28$ & 68 & 30.49 & 166 & 62.64 & & \\
\hline$\geq 28$ & 155 & 69.51 & 99 & 37.36 & 50.15 & $<0.001$ \\
\hline \multicolumn{7}{|l|}{ Smoking } \\
\hline No & 215 & 96.41 & 261 & 98.49 & & \\
\hline Yes & 8 & 3.59 & 4 & 1.51 & 2.18 & 0.14 \\
\hline \multicolumn{7}{|c|}{ Alcohol consumption } \\
\hline No & 211 & 94.62 & 252 & 95.09 & & \\
\hline Yes & 12 & 5.38 & 13 & 4.91 & 0.06 & 0.81 \\
\hline TG (mg/dL) & \multicolumn{2}{|c|}{$255.20 \pm 108.52$} & \multicolumn{2}{|c|}{$269.81 \pm 117.33$} & 1.42 & 0.08 \\
\hline $\mathrm{TC}(\mathrm{mg} / \mathrm{dL})$ & \multicolumn{2}{|c|}{$232.73 \pm 46.42$} & \multicolumn{2}{|c|}{$239.30 \pm 45.70$} & 1.57 & 0.06 \\
\hline HDL-C $(\mathrm{mg} / \mathrm{dL})$ & \multicolumn{2}{|c|}{$50.61 \pm 12.50$} & \multicolumn{2}{|c|}{$53.46 \pm 11.48$} & 2.62 & 0.005 \\
\hline LDL-C (mg/dL) & \multicolumn{2}{|c|}{$113.22 \pm 24.79$} & \multicolumn{2}{|c|}{$122.52 \pm 26.43$} & 3.98 & $<0.001$ \\
\hline
\end{tabular}

BMI, body mass index; TG, triglycerides; TC, total cholesterol; HDL-C, high-density lipoprotein cholesterol; LDL-C, low-density lipoprotein cholesterol.

The gene-environmental analysis was performed to evaluate the role of age, BMI, and levels of HDL-C and LDL-C in the association between the GSTM1 polymorphism and the risk of gestational diabetes mellitus (Table 3 ). However, this gene polymorphism indicated no association with age, BMI, or levels of HDL-C and LDL-C in influencing the susceptibility to gestational diabetes mellitus. 
Table 2. Association between GSTM1, GSTT1, and GSTP1 IIe105Val polymorphisms and development of gestational diabetes mellitus.

\begin{tabular}{|c|c|c|c|c|c|c|c|c|}
\hline Genotypes & Patients $(\mathrm{N}=223)$ & $\%$ & Controls $(\mathrm{N}=265)$ & $\%$ & Chi-square test & P value & OR $(95 \% \mathrm{CI})^{1}$ & P value \\
\hline \multicolumn{9}{|l|}{ GSTM1 } \\
\hline Present & 117 & 52.47 & 178 & 67.17 & & & 1.0 (Reference) & - \\
\hline Null & 106 & 47.53 & 87 & 32.83 & 10.95 & 0.0009 & $1.85(1.26-2.72)$ & $<0.001$ \\
\hline \multicolumn{9}{|l|}{ GSTT1 } \\
\hline Present & 148 & 66.37 & 187 & 70.57 & & & 1.0 (Reference) & - \\
\hline Null & 75 & 33.63 & 78 & 29.43 & 0.99 & 0.32 & $1.21(0.81-1.81)$ & 0.32 \\
\hline \multicolumn{9}{|l|}{ GSTP1 IIe105Val } \\
\hline \multicolumn{9}{|l|}{ Codominant } \\
\hline $\mathrm{IIe} / \mathrm{IIe}$ & 95 & 42.60 & 128 & 48.30 & & & 1.0 (Reference) & - \\
\hline $\mathrm{IIe} / \mathrm{Val}$ & 99 & 44.39 & 109 & 41.13 & & & $1.22(0.82-1.82)$ & 0.30 \\
\hline $\mathrm{Val} / \mathrm{Val}$ & 29 & 13.00 & 28 & 10.57 & 1.78 & 0.41 & $1.40(0.75-2.61)$ & 0.26 \\
\hline \multicolumn{9}{|l|}{ Dominant } \\
\hline $\mathrm{IIe} / \mathrm{IIe}+\mathrm{IIe} / \mathrm{Val}$ & 194 & 87.00 & 237 & 89.43 & & & 1.0 (Reference) & - \\
\hline $\mathrm{Val} / \mathrm{Val}$ & 29 & 13.00 & 28 & 10.57 & 0.70 & 0.40 & $1.27(0.70-2.29)$ & 0.40 \\
\hline \multicolumn{9}{|l|}{ Recessive } \\
\hline $\mathrm{IIe} / \mathrm{IIe}$ & 95 & 42.60 & 128 & 48.30 & & & 1.0 (Reference) & - \\
\hline $\mathrm{IIe} / \mathrm{Val}+\mathrm{Val} / \mathrm{Val}$ & 128 & 57.40 & 137 & 51.70 & 1.59 & 0.21 & $1.26(0.87-1.83)$ & 0.21 \\
\hline
\end{tabular}

${ }^{1}$ Adjusted for age, BMI, HDL-C and LDL-C.

Table 3. Relationship between the GSTM1 polymorphism and demographic and clinical characteristics in the risk of gestational diabetes mellitus.

\begin{tabular}{|c|c|c|c|c|c|c|}
\hline \multirow{2}{*}{ Variables } & \multicolumn{2}{|c|}{ Patients $(\mathrm{N}=223)$} & \multicolumn{2}{|c|}{ Controls $(\mathrm{N}=265)$} & \multirow[t]{2}{*}{ OR $(95 \% \mathrm{CI})$} & \multirow[t]{2}{*}{ P value } \\
\hline & Present (117) & Null (106) & Present (178) & Null (87) & & \\
\hline \multicolumn{7}{|c|}{ Age (years) } \\
\hline$<30$ & 54 & 52 & 105 & 52 & $1.94(1.14-3.33)$ & 0.009 \\
\hline$\geq 30$ & 63 & 54 & 73 & 35 & $1.79(1.00-3.19)$ & 0.03 \\
\hline \multicolumn{7}{|c|}{ BMI $\left(\mathrm{kg} / \mathrm{m}^{2}\right)$} \\
\hline$<28$ & 34 & 34 & 110 & 56 & $1.96(1.06-3.63)$ & 0.02 \\
\hline$\geq 28$ & 83 & 72 & 68 & 31 & $1.90(1.09-3.36)$ & 0.02 \\
\hline \multicolumn{7}{|c|}{ HDL-C $(\mathrm{mg} / \mathrm{dL})$} \\
\hline$<50$ & 56 & 50 & 75 & 37 & $1.81(1.01-3.25)$ & 0.03 \\
\hline$\geq 50$ & 61 & 56 & 103 & 50 & $1.89(1.12-3.20)$ & 0.01 \\
\hline \multicolumn{7}{|c|}{ LDL-C (mg/dL) } \\
\hline$<120$ & 73 & 66 & 82 & 40 & $1.85(1.09-3.17)$ & 0.02 \\
\hline$\geq 120$ & 44 & 40 & 96 & 47 & $1.86(1.03-3.35)$ & 0.03 \\
\hline
\end{tabular}

\section{DISCUSSION}

Gestational diabetes mellitus is a common disease in pregnant women worldwide, and the pathogenesis of this disease is still unclear. In recent years, the important role of genetic predisposition played in lung cancer has promoted substantial interest. Single nucleotide polymorphisms refer to the alteration of a single nucleotide base, by insertion, deletion, or replacement, and thus influence the expression and function of protein (Friedberg, 2003). In this study, we assessed the relationship between GSTM1, GSTT1 and GSTP1 IIe105Val polymorphisms and gestational diabetes mellitus risk in a Chinese population, and we observed that the GSTM1 genetic polymorphism plays an important role in risk of gestational diabetes mellitus in the Chinese population.

The genotype distributions for GSTM1 genetic polymorphisms in control subjects were inconsistent with the results of previous studies in Chinese population (Chiyomaru et al., 2011; Yu et al., 2011; Jiang et al., 2012; Senthilkumar Thirumurugan, 2012; Xu et al., 2013; Li 
et al., 2012, 2015b). The frequency of the GSTM1 null genotype was $32.83 \%$, which is similar to the genotype frequencies observed in Asian population and African American populations (about $30 \%$ ), but is different from that in Caucasians (about 50\%). Previous epidemiologic studies have reported a significant relationship between GSTM1 genetic polymorphisms and development of several kinds of disorders, such as hypertension, hepatotoxicity, type 2 diabetes, ischemic stroke, and cancers (Wang et al., 2012; Gupta et al., 2013; Liu et al., 2013; Eslami and Sahebkar, 2014; Petrovič and Peterlin, 2014; Weich et al., 2015). These studies have shown that the GSTM1 genetic polymorphism could influence the susceptibility to human diseases.

For the correlation between GSTM1 genetic polymorphism and development of gestational diabetes mellitus, only one study investigated their relationship (Orhan et al., 2014). Orhan et al. (2014) carried out a case-control study involving 50 women with GDM and 50 control subjects, and they investigated whether the GSTM1 and GSTT1 genetic variations contributed to susceptibility of gestational diabetes mellitus. However, they did not reveal a statistically significant relationship between the two genetic polymorphisms and gestational diabetes mellitus risk. In our study, we revealed that only the GSTM1 null genotype was correlated with breast cancer risk in a Chinese population, which is inconsistent with previous results. Further studies with large scale sample sizes are greatly needed to verify our results.

In summary, we determined the relationship between GSTM1, GSTT1, and GSTP1 IIe105Val genetic variations and development of gestational diabetes mellitus in a Chinese population. We suggest that the GSTM1 gene polymorphism could influence the susceptibility to gestational diabetes mellitus in a Chinese population.

\section{Conflicts of interest}

The authors declare no conflict of interest.

\section{ACKNOWLEDGMENTS}

We thank the great help from staffs in the Second Affiliated Hospital of Shaanxi University of Chinese Medicine, and the ones who help us to collect the questionnaire from study subjects.

\section{REFERENCES}

American Diabetes Association (2008). Diagnosis and classification of diabetes mellitus. Diabetes Care 31 (Suppl 1): S55-S60.http://dx.doi.org/10.2337/dc08-S055

Anna V, van der Ploeg HP, Cheung NW, Huxley RR, et al. (2008). Sociodemographic correlates of the increasing trend in prevalence of gestational diabetes mellitus in a large population of women between 1995 and 2005. Diabetes Care 31: 2288-2293. http://dx.doi.org/10.2337/dc08-1038

Ao D, Wang HJ, Wang LF, Song JY, et al. (2015). The rs2237892 polymorphism in KCNQ1 influences gestational diabetes mellitus and glucose levels: Acase-control study and meta-analysis. PLoS One 10: e0128901.http://dx.doi. org/10.1371/journal.pone.0128901

Chiyomaru K, Nagano T and Nishigori C (2011). Polymorphisms of glutathione S-transferase in skin cancers in a Japanese population. Kobe J. Med. Sci. 57: E11-E16.

Damm P (1998). Gestational diabetes mellitus and subsequent development of overt diabetes mellitus. Dan. Med. Bull. 45: 495-509.

Eslami S and Sahebkar A (2014). Glutathione-S-transferase M1 and T1 null genotypes are associated with hypertension risk: a systematic review and meta-analysis of 12 studies. Curr. Hypertens. Rep. 16: 432. http://dx.doi.org/10.1007/ $\underline{\text { s11906-014-0432-1 }}$ 
Friedberg EC (2003). DNA damage and repair. Nature 421: 436-440. http://dx.doi.org/10.1038/nature01408

Gupta VH, Singh M, Amarapurkar DN, Sasi P, et al. (2013). Association of GST null genotypes with anti-tuberculosis drug induced hepatotoxicity in Western Indian population. Ann. Hepatol. 12: 959-965.

Hayes JD, Flanagan JU and Jowsey IR (2005). Glutathione transferases. Annu. Rev. Pharmacol. Toxicol. 45: 51-88. http:// dx.doi.org/10.1146/annurev.pharmtox.45.120403.095857

Jiang Z, Liang K, Zhang Q and Tao L (2012). Glutathione S-transferases polymorphisms confer susceptibility to senile cortical cataract in the Han Chinese population. Mol. Vis. 18: 1247-1252.

Khan IA, Movva S, Shaik NA, Chava S, et al. (2014). Investigation of Calpain 10 (rs2975760) gene polymorphism in Asian Indians with Gestational Diabetes Mellitus. Meta Gene 2: 299-306.http://dx.doi.org/10.1016/j.mgene.2014.03.001

Kopp W (2005). Role of high-insulinogenic nutrition in the etiology of gestational diabetes mellitus. Med. Hypotheses 64 : 101-103. http://dx.doi.org/10.1016/j.mehy.2004.06.004

Kühl C (1991). Aetiology of gestational diabetes. Baillieres Clin. Obstet. Gynaecol. 5: 279-292. http://dx.doi.org/10.1016/ $\underline{\text { S0950-3552(05)80098-7 }}$

Li CG, Zhao ZM, Hu MG and Liu R (2012). Predictive role of glutathione-S-transferase gene polymorphisms in risk and prognosis of hepatocellular carcinoma. Asian Pac. J. Cancer Prev. 13: 3247-3252. http://dx.doi.org/10.7314/ APJCP.2012.13.7.3247

Li DD, Su DY, Xue L, Gao W, et al. (2015a). Relationship between a lipoprotein lipase gene polymorphism in placental tissue and insulin resistance in patients with gestational diabetes mellitus. Genet. Mol. Res. 14: 7751-7758. http:// dx.doi.org/10.4238/2015.July.14.1

Li L, Li JG, Liu CY and Ding YJ (2015b). Effect of CYP1A1 and GSTM1 genetic polymorphisms on bone tumor susceptibility. Genet. Mol. Res. 14: 16600-16607.http://dx.doi.org/10.4238/2015.December.11.7

Liu D, Liu Y, Ran L, Shang H, et al. (2013). GSTT1 and GSTM1 polymorphisms and prostate cancer risk in Asians: a systematic review and meta-analysis. Tumour Biol. 34: 2539-2544. http://dx.doi.org/10.1007/s13277-013-0778-z

Metzger BE, Buchanan TA, Coustan DR, de Leiva A, et al. (2007). Summary and recommendations of the fifth international workshop-conference on gestational diabetes mellitus. Diabetes Care 30 (Suppl 2): S251-S260. http:// dx.doi.org/10.2337/dc07-s225

Moon JH, Kwak SH, Jung HS, Choi SH, et al. (2015). Weight Gain and Progression to Type 2 Diabetes in Women With a History of Gestational Diabetes Mellitus. J. Clin. Endocrinol. Metab. 100: 3548-3555. http://dx.doi.org/10.1210/ $\underline{\text { JC.2015-1113 }}$

Orhan O, Atalay MA, Orhan F, Karkucak M, et al. (2014). Glutathione s-transferase $\mathrm{m} 1$ and t1 gene polymorphisms are not associated with increased risk of gestational diabetes mellitus development. West Indian Med. J. 63: 300-306.

Petrovič D and Peterlin B (2014). GSTM1-null and GSTT1-null genotypes are associated with essential arterial hypertension in patients with type 2 diabetes. Clin. Biochem. 47: 574-577. http://dx.doi.org/10.1016/j.clinbiochem.2014.03.012

Savitz DA, Janevic TM, Engel SM, Kaufman JS, et al. (2008). Ethnicity and gestational diabetes in New York City, 19952003. BJOG 115: 969-978. http://dx.doi.org/10.1111/j.1471-0528.2008.01763.x

Sella T, Shalev V, Elchalal U, Chovel-Sella A, et al. (2013). Screening for gestational diabetes in the 21st century: a population-based cohort study in Israel. J. Matern. Fetal Neonatal Med. 26: 412-416. http://dx.doi.org/10.3109/147 $\underline{67058.2012 .733761}$

Senthilkumar KP and Thirumurugan R (2012). GSTM1 and GSTT1 allele frequencies among various Indian and nonIndian ethnic groups. Asian Pac. J. Cancer Prev. 13: 6263-6267. http://dx.doi.org/10.7314/APJCP.2012.13.12.6263

Strange RC, Lear JT and Fryer AA (1998). Glutathione S-transferase polymorphisms: influence on susceptibility to cancer. Chem. Biol. Interact. 111-112: 351-364. http://dx.doi.org/10.1016/S0009-2797(97)00172-5

Takhshid MA, Haem Z and Aboualizadeh F (2015a). The association of circulating adiponectin and $+45 \mathrm{~T} / \mathrm{G}$ polymorphism of adiponectin gene with gestational diabetes mellitus in Iranian population. J. Diabetes Metab. Disord. 14: 30. http:// dx.doi.org/10.1186/s40200-015-0156-Z

Takhshid MA, Zahediannejad Z, Aboualizadeh F, Moezzi L, et al. (2015b). G22A polymorphism of adenosine deaminase and its association with biochemical characteristics of gestational diabetes mellitus in an Iranian population. Iran. J. Med. Sci. 40: 170-174.

Wang R, Wang Y, Wang J and Yang K (2012). Association of glutathione S-transferase T1 and M1 gene polymorphisms with ischemic stroke risk in the Chinese Han population. Neural Regen. Res. 7: 1420-1427.

Weich N, Nuñez MC, Galimberti G, Elena G, et al. (2015). Polymorphic variants of GSTM1, GSTT1, and GSTP1 genes in childhood acute leukemias: A preliminary study in Argentina. Hematology 20: 511-516. http://dx.doi.org/10.117 9/1607845415Y.0000000007

Xu XB, Liu SR, Ying HQ and A ZC (2013). Null genotype of GSTM1 and GSTT1 may contribute to susceptibility to male infertility with impaired spermatogenesis in Chinese population. Biomarkers 18: 151-154. http://dx.doi.org/10 $.3109 / 1354750 X .2012 .755221$

Yu L, Wang CY, Xi B, Sun L, et al. (2011). GST polymorphisms are associated with hepatocellular carcinoma risk in Chinese population. World J. Gastroenterol. 17: 3248-3256. 